Mirete, A.B., Belmonte, M.L. \& Maquilón, J.J. (2020). Diseño, aplicación y validación de un instrumento para Valorar las Actitudes hacia la Diversidad del Alumnado (VADA). Revista Electrónica Interuniversitaria de Formación del Profesorado, 23(2), 185-207.

DOI: https://doi.org/10.6018/reifop.413851

\title{
Diseño, aplicación y validación de un instrumento para Valorar las Actitudes hacia la Diversidad del Alumnado (VADA)
}

Ana B. Mirete, $M^{a}$ Luisa Belmonte, Javier J. Maquilón

Departamento de Métodos en Investigación y Diagnóstico en Educación

Universidad de Murcia

\section{Resumen}

La diversidad es una realidad inherente a nuestra Sociedad, imprescindible para el logro de una comunidad justa e igualitaria. Conocer las actitudes hacia la diversidad resulta ser un elemento imprescindible para la articulación de medidas que faciliten el respeto hacia la diferencia. El objetivo de esta investigación se centró en diseñar, aplicar y validar un instrumento para valorar la actitud hacia la diversidad en escolares menores de seis años. Se contó con la participación de 125 estudiantes de edades comprendidas entre tres y seis años, así como con seis expertos en metodología de investigación y en atención a la diversidad para la validación interjueces del instrumento. Los resultados apuntan a que los estudiantes muestran una actitud positiva hacia la diversidad, pero consideran que la capacidad académica de los escolares con discapacidad es una gran limitación. Estos resultados evidencian la necesidad de intervenir educativamente para eliminar prejuicios y para construir un nuevo conocimiento basado en la igualdad de la diferencia.

\section{Palabras clave}

Actitud hacia la diversidad; educación infantil; validación de instrumento; inclusión educativa.

\section{Contacto:}

Ana Belén Mirete Ruiz, anabelen.mirete@um.es, Departamento MIDE - Facultad de Educación. Universidad de Murcia (España). 


\title{
Design, application and validation of an instrument to assess attitudes towards student diversity
}

\begin{abstract}
Diversity is intrinsic to our society, fundamental to the creation of a fair and egalitarian community. Understanding attitudes towards diversity is an essential element for the establishment of measures to facilitate respect for diversity. The aim of this research focused on designing, applying and validating an instrument to assess attitudes towards diversity in students younger than six years old. A group of 125 students of ages ranging between three and six participated in the study. Additionally, six experts in the fields of research methodology and attention to diversity were chosen as inter-judges to determine the validity of the instrument. Results show that students display a positive attitude towards diversity, but that they consider lack of academic ability in students with disabilities to be a considerable limitation. These findings prove the need to start an educational intervention to eliminate prejudices and build new knowledge based on the equality of diversity.
\end{abstract}

\section{Key words}

Attitude towards diversity; infant education; instrument validation; educational inclusión.

\section{Introducción}

Un profundo proceso de cambio viene acaeciendo estos últimos años en el sistema pedagógico dado el número, cada vez mayor, de estudiantes con necesidades educativas escolarizados en centros ordinarios (Rello et al., 2020). Este movimiento transformador focaliza los esfuerzos en orientar su brújula hacia la inclusión dentro de las aulas, para lograr una educación de calidad y calidez para todos los niños, sin exclusión alguna (Zambrano \& Orellana, 2018). Para ello, presta especial atención a las personas con diversidad funcional, por su situación de desventaja al presentar una discapacidad (láñez, 2009) y ser uno de los grupos sociales más vulnerables de padecer exclusión (Latorre \& Liesa, 2016). Desde hace décadas este colectivo ha expresado su deseo de participar en actividades comunitarias y tener un grupo de amigos estable (Froese et al., 1999). Aunque no se puede alejar la vista del gran esfuerzo que entraña el lograr una sociedad inclusiva en la que toda persona tenga la posibilidad de participar y contribuir a su desarrollo (Belmonte \& García-Sanz, 2013), ya que, desgraciadamente, gran parte de las trabas con las que luchan a diario las personas con diversidad funcional, se hallan en el entorno social (láñez, 2009). Es más, este colectivo se caracteriza por ser uno de los grupos sociales con mayor índice de marginación (Polo \& Aparicio, 2018).

De forma paralela a estos hechos, socialmente hablando, se trabaja arduamente en la tarea de localizar y modificar posibles barreras sociales para estas personas, ya que los beneficios de la erradicación de las mismas, pueden resultar incluso mayores que las intervenciones a nivel individual (Bodde \& Seo, 2009). Así pues, diferentes autores defienden que el éxito de la inclusión se encuentra directamente relacionado con la eliminación de barreras conductuales, más incluso que con la implantación de medidas legales, por ser la actitud un determinante de la personalidad y las acciones humanas (Rodríguez \& Fernández, 2017), además de una de las trabas más poderosas para la aceptación de las personas con discapacidad (Downs \& Williams, 1994; Lee \& Rodda, 1994; Shannon et al., 2009). Otros 
autores afirman que la diversidad es enriquecedora y necesaria para el progreso, las relaciones sociales y comunitarias han de desarrollarse en condiciones de equidad y justicia social (Rodríguez \& Fernández, 2017), siendo el ambiente adecuado para trabajarlo, el contexto educativo (Calvo, 2008), ya que es necesario el fomento de la igualdad, junto con actividades y tareas con metas y objetivos comunes, para potenciar actitudes positivas (Pettigrew \& Trop, 2006; Wong, 2008).

Se conciben las actitudes como pensamientos, sentimientos, opiniones, expectativas, maneras de comportarse y reaccionar que se ponen de manifiesto de forma distinta según el referente (Arias et al., 2016). En este sentido, y dado que las actitudes no son innatas, sino que son aprendidas a través de las experiencias, son susceptibles de ser educadas (Escámez et al., 2007) y evaluadas.

Conocer las actitudes de los estudiantes hacia la diversidad supone un aspecto fundamental para poder intervenir adecuadamente hacia la construcción de creencias positivas que faciliten un mayor conocimiento y respeto hacia la diferencia y modificando aquellas que puedan promover la discriminación (Flórez et al., 2009; Nowicki, 2006).

Existe un gran número de investigaciones relacionadas con las actitudes de estudiantes hacia sus compañeros con discapacidad (Avramidis \& Norwich, 2000; Brown et al., 2011; Litvack et al., 2011; Gómez \& Infante, 2004; Nowicki, 2006; Slininger et al., 2000; Vignes et al., 2009; Yazbeck et al., 2004), que han evidenciado que dichas actitudes se encuentran siempre en continuo cambio, aunque es en el periodo escolar donde los jóvenes las consolidan y por tanto, donde las intervenciones dirigidas a dar forma a esas actitudes tienen mayor impacto (Aguado et al., 2008; Cameron et al., 2011; Jeon, 2018; Lindsay \& Edwards, 2013) ya que las actitudes negativas hacia la diversidad surgen a edades muy tempranas (Magiati et al., 2002; Maras \& Brown, 2000; Nowicki \& Sandieson, 2002).

La educación en valores y la construcción de actitudes positivas hacia la diversidad es considerada primordial para ir forjando una escuela enmarcada bajo el principio de inclusión. A edades tempranas, durante la infancia (de cero a seis años) es considerada como la etapa vital más propicia para que la educación influya en la construcción de ciudadanos capaces de conocer sus derechos y obligaciones ante los demás (Graziella \& Rivera, 2018).

Resulta necesario construir una Sociedad inclusiva que promueva y garantice oportunidades de aprendizaje para todos, se parte de la construcción de valores solidarios fundamentados por actitudes positivas hacia la diversidad humana. Se pretende lograr que los sistemas educativos ofrezcan una educación inclusiva que garantice la equidad, la calidad y el éxito para todos (UNESCO, 2017). Se ha demostrado que la educación es un elemento clave en la transformación hacia una sociedad inclusiva, convirtiéndose la inclusión, en sí misma, en un reto específico a conseguir (Ainscow et al., 2016; European Agency for Special Needs and Inclusive Education, 2014).

Escámez et al. (2007) afirma que las actitudes son cambiantes y educables, pero para que llegue a producirse un cambio de actitud positivo hacia la diversidad (Navas et al., 2004; Nikolaraizi \& De Reybekiel, 2001; Wong, 2008), no es suficiente con que escolares diversos y no diversos compartan aula de clase, pese a ser conveniente y positivo (Huete et al., 2010; Peralta, 2007). En otros contextos (Rillota \& Nettelbeck, 2007), esta relación positiva ha sido establecida no en un contexto de aula, sino con la globalidad de la comunidad educativa y se ha asociado al éxito de la institución educativa hacia la inclusión.

El problema es que no existen instrumentos que arrojen claridad sobre la situación existente en las aulas de Educación Infantil. Por ello, consideramos que han de tenerse en 
cuenta una serie de aspectos antes de elaborar o identificar los medios, procedimientos e instrumentos de recogida de información que podrían ser empleados con escolares menores de seis años:

- Proceso lecto-escritor inmaduro

- Léxico reducido a nivel expresivo. Dificultad de expresión oral en cuanto a conocimientos, actitudes, sentimientos, motivaciones, intereses, etc.

- Léxico reducido a nivel comprensivo. Dificultad en comprensión de enunciados

- Dificultad para establecer juicios de valor

- Influencia inmediata del grupo de iguales tanto a favor como en contra sobre cualquier aspecto

- Limitaciones con la atención focalizada, sostenida y selectiva

La finalidad de este trabajo es doble, la primera ofrecer pautas para la construcción de cuestionarios dirigidos a estudiantes prelectores, y la segunda, diseñar y validar un instrumento para valorar las actitudes hacia la diversidad de estudiantes entre tres y seis años. Así se podrá identificar la actitud hacia la diversidad en los estudiantes y dar respuesta al objetivo de la investigación.

\section{Método}

\section{Participantes}

En la investigación se ha recabado información de dos grupos de participantes:

1) Expertos en el proceso de validación de contenido del instrumento, constituido por tres expertos en metodología de la investigación y tres expertos en atención a la diversidad, todos profesores y profesoras de la Universidad de Murcia.

2) Escolares con edades comprendidas entre los tres y seis años. Se contó con 125 escolares de segundo ciclo de Educación Infantil, de los cuales 28 (22,4\%) corresponden al primer nivel ( 3 años) y colaboraron en la revisión del contenido de la propuesta inicial de instrumento VADA. Los 97 escolares restantes, $48(38,4 \%)$ cursaban segundo nivel (4 años) y 49 (39,2\%) tercer nivel de Educación Infantil (5 años) a los que se les aplicó la versión revisada del VADA.

\section{Instrumento y estrategias de análisis de información}

El instrumento objeto de este estudio, fue un cuestionario diseñado específicamente para Valorar las Actitudes hacia la Diversidad del Alumnado (VADA). Este cuestionario (Anexo 1) consta, en su versión final, con 10 ítems, los cuales están presentados de manera gráfica, además de su correspondiente enunciado.

La estructura de los ítems se corresponde con una secuencia de dos imágenes que muestran una historia a la cual, el encuestado, ha de indicar el desenlace que considere que sucederá. Dicho desenlace o final de la historia consta también de dos viñetas, una con un carácter o intención inclusiva, y otra con perfil segregador o no inclusivo.

\section{Análisis de los datos}

Los datos obtenidos fueron analizados con el paquete estadístico SPSS en su versión 22. Se realizaron los siguientes estadísticos: estudio descriptivo en términos de frecuencias y 
porcentajes; medidas de fiabilidad empleando el estadístico Alpha de Cronbach; y análisis de consistencia interjueces, para lo cual se aplicó la prueba de correlación de Kendall.

\section{Procedimiento}

El procedimiento de investigación seguido obedece a las siguientes fases:

\section{Fase 1. Elaboración del instrumento.}

La construcción del instrumento parte de una revisión de investigaciones orientadas al diseño de instrumentos específicos para la medición de las actitudes hacia la discapacidad. Así, se revisaron los trabajos presentados por Novo et al. (2015) o Suriá (2011), los cuales se centraban en medir dichas actitudes presentes en estudiantes universitarios. Igualmente, se han valorado los estudios realizados por Macías-Gómez (2016), Macías-Gómez et al. (2019), Ossa (2013) o Polo et al. (2011), entre otros, los cuales han empleado en sus investigaciones la escala de actitudes hacia la discapacidad, revisada recientemente por sus autores (Arias et al., 2016). En todos ellos se valoran las actitudes de estudiantes en etapas de Educación Superior. Finalmente, y en un contexto más similar al objeto de esta investigación, se han analizado los trabajos realizados por Surriá (2011) y López \& Lozano (2016), ambos centrados en analizar las actitudes hacia la discapacidad en estudiantes de la etapa de Educación Secundaria Obligatoria, o el de Alcedo et al. (2013), en el cual diseñaron y validaron un instrumento compuesto por 36 ítems, destinado a niños de edades comprendidas entre los siete y los diez años.

Arias et al. (2016) publicaron un meta-análisis de instrumentos destinados a valorar las actitudes hacia la discapacidad a nivel internacional. Del total de 66 instrumentos objetos de revisión, el $15 \%$ tuvo como destinatarios a población infantil, pero ninguno dirigido a escolares no lectores.

Esposito \& Peach (1983) emplearon un guion de entrevista que podría ser empleado con escolares que no han adquirido los requisitos básicos de lecto-escritura.

Así, siguiendo el procedimiento general para la construcción y aplicación de instrumentos cuantitativos de recogida de información (Cubo et al, 2011; McMillan \& Schumacher, 2005), y tomando como base la escala de actitudes sociales y profesionales hacia las personas con discapacidad (Arias et al., 2016), y el Inventario de Actitudes hacia Personas con Discapacidad (Alcedo et al., 2013), se procedió a la selección de aquellos ítem que más se ajustaban al contexto educativo y social de los estudiantes de menor edad.

Seguidamente, y tras un trabajo colaborativo dentro del grupo de investigación, se redujo dicha selección y se procedió a la adaptación de un total de 10 ítems. Con ellos se configuró la primera versión del instrumento y se determinaron las secuencias gráficas que acompañarían a cada uno de los ítem. Dicha secuencia consta de un total de cuatro viñetas, las cuales han sido diseñadas y dibujadas con la finalidad de presentar de manera visual el contenido de cada enunciado.

\section{Fase 2. Contacto con el centro y consentimiento para el estudio}

Una vez diseñada la primera versión del instrumento, se contactó con un centro educativo, para solicitar autorización para la realización del estudio. Tras una reunión explicativa con el Equipo Directivo, se obtuvo el consentimiento informado para la participación en la investigación.

También se tuvo en cuenta la responsabilidad ética que todo investigador asume, máxime cuando se interviene con seres humanos (McMillan \& Schumacher, 2005), por ello, no solo se informó debidamente a los responsables del centro educativo del procedimiento a llevar a cabo, sino que se respetó la decisión de los participantes de colaborar en el estudio o 
abandonarlo si ese era su deseo. Se aseguró el bienestar físico y mental de todos los implicados, y se trató la información con garantía de confidencialidad y anonimato.

\section{Fase 3. Validación de contenido.}

Seguidamente se remitió el instrumento VADA a los expertos para realizar la validación de contenido. Se les facilitaron los ítems en su conjunto y las secuencias de imágenes de manera individual. También se les remitió una plantilla de valoración que tuvo en cuenta los criterios de pertinencia, claridad, coherencia y adecuación de cada ítem.

Con las recomendaciones y propuestas de mejora de los expertos se diseñó la versión definitiva del VADA que se incluye en el Anexo.

\section{Fase 4. Estudio piloto.}

La realización del estudio piloto se realizó en dos momentos. En el primero, los participantes que cursaban el primer nivel ( 3 años) fueron exponiendo en pequeños grupos qué veían en las secuencias gráficas, pudiendo determinar posibles sesgos en la interpretación de las mismas y sus respectivos desenlaces. La finalidad fue asegurar la comprensión visual de cada una de las secuencias gráficas de los ítems.

En un segundo momento, se aplicó el instrumento a 97 escolares de segundo y tercer nivel de Educación Infantil (cuatro y cinco años). Se analizaron los datos para dar respuesta a los objetivos de la investigación.

\section{Resultados}

Los resultados se presentan según las fases de la investigación que coinciden con los objetivos específicos. De este modo se evita la pérdida de coherencia entre los mismos.

En primer lugar, el análisis de la versión inicial del VADA por los expertos concluyó con la modificación/matización de la totalidad de ítems en cuanto a la redacción y a las viñetas de historia y de desenlace. Ahora bien, la prueba de correlación de Kendall empleada para el análisis de concordancia entre expertos, muestra una que las valoraciones de todos los evaluadores están en consonancia $(p<, 001)$, habiendo obtenido en todos los ítems analizados una puntuación media superior a 3,80 sobre 5 puntos.

Durante la primera fase del estudio piloto se pudo constatar que el cuestionario era comprensible por niños y niñas de tres y cuatro años de edad. Todos indicaron con claridad lo que observaban en las viñetas, mostraron un elevado nivel de comprensión de las imágenes de respuesta, tanto en aquellas que reflejaban una actitud positiva hacia la inclusión, como las de carácter negativo.

Dado que los ítems del instrumento van acompañados de una escala dicotómica, no puede realizarse un análisis factorial confirmatorio que determine la dimensionalidad del cuestionario. Por ello, se estableció teóricamente en torno a tres factores: (1) competencia académica, (2) relación interpersonal, y (3) organización de aula.

Tras la revisión del instrumento, la elaboración de la segunda versión del VADA, y su posterior aplicación, se pudo obtener los datos que confirmaron su adecuada consistencia interna. Se empleó el método basado en la covariación de los ítems, el Alfa de Cronbach, con un valor de ,68. Se confirmó la imposibilidad de mejorar dicho valor eliminando alguno de los ítems. 
Para dar respuesta al objetivo que analiza la actitud hacia la diversidad de los escolares prelectores, se realizó un análisis descriptivo que se presenta en la tabla 1, es de destacar que en ocho de los diez ítems se supera el 75\% de respuesta positiva hacia la inclusión.

Por otro lado, en los ítems cinco y siete, se obtuvo un porcentaje de respuesta negativa del $33 \%$ y $41,2 \%$ respectivamente, ambos ítems relacionados con la capacidad de aprendizaje de los estudiantes con discapacidad.

Tabla 1.

Frecuencia y porcentaje de respuesta por ítem

Ítem

1.- En la escuela, un estudiante con discapacidad es capaz de $\begin{array}{llll}\text { No } & 16 & 16,8\end{array}$

\begin{tabular}{lllll}
\cline { 2 - 4 } seguir instrucciones complejas & Sí & 79 & 83,2
\end{tabular}

2.- Los niños y niñas diferentes deberían poder divertirse con los \begin{tabular}{lll} 
No & 22 & 22,9 \\
\cline { 2 - 3 }
\end{tabular}

demás niños

\begin{tabular}{llll}
\hline 3.- Me gusta jugar junto a niños y niñas diferentes & No & 19 & 19,6
\end{tabular}

\begin{tabular}{rrrr} 
Sí & 78 & 80,4 \\
\hline
\end{tabular}

4.- A los niños y niñas con discapacidad se debe permitir $\begin{array}{llll}\text { No } & 17 & 17,5\end{array}$

\begin{tabular}{lllll}
\cline { 2 - 4 } participar en actividades grupales & Sí & 80 & 82,5
\end{tabular}

5.- Los niños y niñas con discapacidad pueden ser estudiantes $\begin{array}{llll}\text { No } & 32 & 33,0\end{array}$

\begin{tabular}{lllll}
\cline { 2 - 4 } competentes en sus aprendizajes & Sí & 65 & 67,0
\end{tabular}

6.- No me importa estar cerca de niños que parecen diferentes o \begin{tabular}{rrrr} 
No & 11 & 11,3 \\
\cline { 2 - 4 }
\end{tabular}

\begin{tabular}{lllll}
\cline { 2 - 4 } actúan de forma distinta & Sí & 86 & 88,7 \\
\hline
\end{tabular}

7.- De los estudiantes con discapacidad puede esperarse lo $\begin{array}{llll}\text { No } & 40 & 41,2\end{array}$

\begin{tabular}{lllll}
\cline { 2 - 4 } mismo que de los que no la tienen & Sí & 57 & 58,8
\end{tabular}

8.- Es apropiado que los niños y niñas con discapacidad jueguen $\begin{array}{llll}\text { No } & 21 & 21,6\end{array}$

\begin{tabular}{lllll}
\cline { 2 - 4 } con todos los demás & Sí & 76 & 78,4 \\
\hline
\end{tabular}

9.- Los niños y niñas diferentes pueden ser igual de capaces $\quad$ No $\quad \begin{array}{rrr}17 & 18,1\end{array}$

\begin{tabular}{lllll}
\cline { 2 - 4 } académicamente que los demás estudiantes & Sí & 77 & 81,9
\end{tabular}

$\begin{array}{lllll}\text { 10.- Me gusta realizar actividades en el colegio con niños y niñas } & \text { No } & 12 & 12,4\end{array}$

diferentes \begin{tabular}{llll}
\cline { 2 - 4 } & Sí & 85 & 87,6 \\
\hline
\end{tabular}

\section{Discusión y conclusiones}

Contar con instrumentos de recogida de datos válidos y fiables es una constate de toda investigación. Su diseño, en muchas ocasiones, se convierte en una tarea compleja por diferentes factores, ya sea por el constructo de estudio, el proceso de validación, la identificación de variables, o, como aquí se ha evidenciado, las características de los destinatarios (Mirete et al., 2019).

Tras la ejecución de un proceso riguroso y sistemático, se ha elaborado y validado un instrumento fiable para medir las actitudes hacia la diversidad en niños de edades tempranas, ya sean pre-lectores o se encuentren en proceso de adquisición de la lectoescritura.

Coincidimos con McDougall et al. (2004) en afirmar la coexistencia de actitudes de aceptación y de rechazo entre los estudiantes hacia la diversidad, reclamando la necesidad de que los centros escolares generen una estructura que promueva el éxito en las tareas y las relaciones positivas entre estudiantes con y sin discapacidad. 
Se confirma que, a edades tempranas, las actitudes hacia la diversidad son mayoritariamente positivas, el nivel de aceptación hacia las personas diversas y su interacción interpersonal es mayor. No obstante, la edad es un factor que influye negativamente en la actitud hacia la inclusión y la aceptación de la diversidad (Hugh et al, 2012; Nowicki, 2006), empeorando a medida que los escolares se hacen mayores, especialmente a partir de la preadolescencia. Campbell et al. (2004), confirmaron empíricamente una correlación negativa pero estadísticamente significativa entre la edad y actitud hacia la diversidad en escolares de edades entre 8 y 12 años.

Un porcentaje elevado de escolares considera que las capacidades académicas de los estudiantes con discapacidad son una limitación no superable. Ahora bien, sí aceptan y consideran positiva la relación interpersonal y la actividad escolar conjunta. Investigadores de esta línea (García \& Hernández, 2011; Laws \& Kelly, 2005; Polo et al., 2011) han puesto de manifiesto que la tolerancia, el respeto y la aceptación de la diferencia aumentan cuando existen más oportunidades de conocer y comprender lo que significa la discapacidad. Es por ello, que resulta necesaria la erradicación de ciertos estereotipos que minan la integración educativa de las personas con discapacidad, favoreciendo la formación de los más pequeños hacia la igualdad de la diferencia, a fin de ir consolidando un conocimiento real sobre la discapacidad, alejada de prejuicios y falsas concepciones.

Como limitación de la investigación podría cuestionarse el índice de fiabilidad del instrumento VADA, tradicionalmente en investigación educativa (George \& Mallery, 2003) debe ser superior a ,70. Otros autores consideran que valores en torno a ,60 son aceptables para investigación descriptiva en educación (McMillan \& Schumacher, 2005) ya que se garantiza la consistencia interna del instrumento en cuestión. En este sentido, una fiabilidad de ,68 es aceptable para considerar válidos los resultados y conclusiones presentadas. Deben tenerse en cuenta el resto de aspectos que configuran el estudio, como es la complejidad que conlleva acceder a escolares de edades inferiores a seis años, que estos escolares se están iniciando el proceso lector, que el instrumento que se les presenta es de cumplimentación en lápiz y papel, y que se están iniciando en la comprensión de fenómenos complejos, como es la consolidación de las actitudes hacia la diversidad.

\section{Referencias}

Aguado, A.L., Alcedo, M.A. \& Arias, B. (2008). Cambio de actitudes hacia la discapacidad con escolares de Primaria. Psicothema, 20(4), 697-704. http://www.psicothema.com/psicothema.asp?id=3543

Ainscow, M., Dyson, A. \& Weiner, S. (2013). From Exclusion to Inclusion: a review of international literature on ways of responding to students with special educational needs in schools. En-clave pedagógica: Revista Internacional de Investigación $e$ Innovación Educativa, 13, 13-30. https://eric.ed.gov/?id=ED546818

Alcedo, M., Gómez, L. E., Aguado, A., Arias, B. \& González, R. (2013). Eficacia del contacto e información como técnicas de cambio de actitudes hacia personas con discapacidad en niños de Educación Primaria. Universitas Psychologica,12(2), 493-504. doi: 10.11144/Javeriana.UPSY12-2.ecit

Arias, V., Arias, B., Verdugo, M.A., Rubia, M. \& Jenaro, C. (2016). Evaluación de actitudes de los profesionales hacia las personas con discapacidad. Siglo Cero, 47(2), 7-41. doi: $10.14201 /$ scero2016472741 
Avramidis, E. \& Norwich, B. (2000). Teachers' Attitudes toward Integration/Inclusion: A Review of the Literature. European Journal of Special Needs Education, 17(2), 129-148. https://doi.org/10.1080/08856250210129056

Belmonte, M.L. \& García-Sanz, M.P. (2013). La escuela de vida, otra mirada a la discapacidad intelectual. Revista $\quad$ Fuentes, 14, 147-170. https://revistascientificas.us.es/index.php/fuentes/article/view/2357

Bodde, A.E. \& Seo, D.C. (2009). A review of social and environmental barriers to physical activity for adults with intellectual disabilities. Disability and Health Journal, 2(2), 5766. doi: http://dx.doi.org/10.1016/j.dhjo.2008.11.004

Brown, H.K., Ouellette-Kuntz, H., Lysaght, R. \& Burge, P. (2011). Students' behavioural intentions towards peers with disability. Journal of Applied Research in Intellectual Disabilities, 24(4), 322-332. doi: http://dx.doi.org/10.1111/j.1468-3148.2010.00616.x

Calvo, T. (2008). Actitudes ante la Inmigración y cambio de valores. Madrid: UCM.

Cameron, L., Rutland, A., Turner, R., Holman, R. \& Powell, C. (2011). Changing attitudes with a little imagination: imagined contact effects on young children's intergroup bias. Anales de Psicología, 27(3), 708-717. http://dx.doi.org/10.6018/analesps

Campbell, J.M., Ferguson, J.E., Herzinger, C.V., Jackson, J.N. \& Marino, C.A. (2004). Combined descriptive and explanatory information improves peers' perceptions of autism. Research in developmental disabilities, 25(4), 321-339. doi: 10.1016 / j.ridd.2004.01.005

Cubo, S., Martín, B. \& García, J.L. (Coord.) (2011). Métodos de investigación y análisis de datos en ciencias sociales y de la salud. Ediciones Pirámide Grupo Anaya.

Downs, P. \& Williams, T. (1994). Student attitudes toward integration of people with disabilities in activity settings: a European comparison. Adapted Physical Activity Quarterly, 11(1), 32-43. doi: 10.1123/apaq.11.1.32

Escámez, J., García, R., Pérez, C. \& Llopis, A. (2007). El aprendizaje de valores y actitudes. Teoría y práctica. Madrid: Octaedro/OEI.

European Agency for Special Needs and Inclusive Education (2014). Five Key Messages for Inclusive Education. Putting Theory into Practice. Odense, Denmark: European Agency for Special Needs and Inclusive Education.

Flórez, M.A., Aguado, A.L. \& Alcedo, M.A. (2009). Revisión y análisis de los programas de cambio de actitudes hacia personas con discapacidad. Anuario de Psicología Clínica y de la Salud, 5, 85-98. https://dialnet.unirioja.es/servlet/articulo?codigo=3328258

Froese, P., Richardson, M., Romer, L. \& Swank, M. (1999). Comparing opinions of people with developmental disabilities and significant people in their lives using the individual supports identification system (ISIS). Disability and Society, 14, 831-43. doi: 10.1080/09687599925920

García, L.G.A. \& Hernández, O.S. (2011). Actitudes hacia la discapacidad de jóvenes y adultos de Chiapas. Universitas Psychologica, 10(3), 817-827. https://www.redalyc.org/pdf/647/64722377014.pdf

George, D. \& Mallery, P. (2003). SPSS for Windows step by step: A Simple Guide and Reference. 11.0 Update ( $4^{\mathrm{a}}$ ed.). Allyn \& Bacon. 
Gómez, V. \& Infante, M. (2004). Actitudes de los estudiantes de educación hacia la integración de personas con discapacidad y hacia la educación multicultural. Cultura y educación, 16(4), 371-383. https://doi.org/10.1174/1135640042802455

Graziella, O. \& Rivera, J.R. (2018). Construcción de ciudadanía: la educación desde la infancia encaminada a la inclusión social. Tla-Melaua, revista de Ciencias Sociales. Facultad de $\begin{array}{llll}\text { Derecho } & y & \text { Ciencias } & \text { 52-71. }\end{array}$ http://www.scielo.org.mx/scielo.php?script=sci_abstract\&pid=S187069162018000100052\&lng=es\&nrm=iso

Huete, A., Sola, A. \& Lara, P. (2010). Los jóvenes con discapacidad en España. Informe de situación 2010. Madrid: CERMI.

Hugh, G., Guardia, S., Pires, M. \& Rault, C. (2012). Attitudes towards Down Syndrome: A national comparative study in France, Ireland, Portugal and Spain. Irish Journal of Psychology 21(3). 203-214. doi: 10.1080/03033910.2000.10558253

láñez, A. (2009). Vida independiente y diversidad funcional. Resultados de una investigación social aplicada en la provincia de Sevilla. Portularia, 9(1), 93-103. http://riberdis.cedd.net/handle/11181/3997

Jeon, M. (2018). Meta-analysis of disability simulation research for elementary students in Korea. International Journal of Special Education, 33(1), 140-151. https://files.eric.ed.gov/fulltext/EJ1184078.pdf

Latorre, C. \& Liesa, M. (2016). La inclusión social de personas con diversidad funcional en una experiencia de vida independiente. Revista de educación inclusiva, 9(2), 171-185. https://www.revistaeducacioninclusiva.es/index.php/REl/article/view/278

Laws, G. \& Kelly, E. (2005). The attitudes and friendship intentions of children in United Kingdom Mainstream Schools towards peers with physical or intellectual disabilities. International Journal of Disability, Development and Education, 52(2), 79-99. https://doi.org/10.1080/10349120500086298

Lee, T. \& Rodda, M. (1994). Modification of attitudes toward people with disabilities. Canadian Journal of Rehabilitation, 7(4), 229-238. https://psycnet.apa.org/record/199513508-001

Lindsay, S. \& Edwards, A. (2013). A systematic review of disability awareness interventions for children and youth. Disability \& Rehabilitation, 35(8), 623-646. https://doi.org/10.3109/09638288.2012.702850

Litvack, M.S., Ritchie, K.C. \& Shore, B.M. (2011). High and averageachieving students' perceptions of disabilities and of students with disabilities in inclusive classrooms. Exceptional Children, 77(4), 474-487. https://doi.org/10.1177/001440291107700406

López, M.P. \& Lozano, M. (2016). Mejora de las actitudes hacia las personas con discapacidad en el alumnado de Educación Secundaria Obligatoria. International Journal of Developmental and Educational Psychology, 1, 221-224. http://dx.doi.org/10.17060/ijodaep.2016.n1.v1.205

Macías-Gómez, M.E. (2016). Actitudes de estudiantes de magisterio en educación primaria hacia las personas con discapacidad. Revista nacional e internacional de educación inclusiva, 9(1), 54-69. https://revistaeducacioninclusiva.es/index.php/REI/article/view/70

Macías-Gómez, M.E., Aguilera, J.L., Rodríguez, M. \& Gil, S. (2019). Un estudio transversal sobre las actitudes de los estudiantes de pregrado y máster en ciencias de la 
educación hacia las personas con discapacidad. Revista Electrónica Interuniversitaria de Formación del Profesorado, 22(1), 225240. https://doi.org/10.6018/reifop.22.1.353031

Magiati, I., Dockrell, J. \& Longotheti, A. (2002). Young children's understanding of disabilities: The influence of development, context and cognition. Applied Developmental Psychology, 23(4), 409-430. https://doi.org/10.1016/S01933973(02)00126-0

Maras, P. \& Brown, R. (2000). Effects of different forms of school contact on children's attitudes toward disabled and non-disabled peers. British Journal of Educational Psychology, 70(3), 337-351. https://doi.org/10.1348/000709900158164

McDougall, J., DeWit, D.J., King, G., Miller, L.T. \& Killip, S. (2004). High school-aged youth's attitudes toward their peers with disabilities: The role of school and student interpersonal factors. International Journal of Disability, Development and Education, 51(3), 287-313. https://doi.org/10.1080/1034912042000259242

McMillan, J. \& Schumacher, S. (2005). Investigación educativa. PEARSON.

Mirete, A. B., Alcaraz, S., Caballero, C.M. \& Arnaiz, P. (2019). Diseño y validación de un instrumento para escuchar la voz del alumnado de las aulas abiertas especializadas. Publicaciones, 49(3), 79-117. doi:10.30827/publicaciones.v49i3.11405

Navas, L., Torregrosa, G. \& Mula, A. (2004). Algunas variables predictoras de las actitudes del alumnado ante la integración escolar. Revista de Psicología Social, 19(2), 159-171. https://doi.org/10.1174/021347404773820963

Nikolaraizi, M. \& De Reybekiel, N. (2001). A comparative study of children's attitudes towards deaf children, children in wheelchairs and blind children in Greece and in the UK. European Journal of Special Needs Education, 16(21), 167-182. https://doi.org/10.1080/08856250110041090

Novo, I., Muñoz, J. \& Calvo, C. (2015). Los futuros docentes y su actitud hacia la inclusión de personas con discapacidad. Una perspectiva de género. Anales de psicología, 1, 155171. https://doi.org/10.6018/analesps.31.1.163631

Nowicki, E.A. (2006). A cross-sectional multivariate analysis of children's attitudes towards disabilities. Journal of Intellectual Disability Research, 50(5), 335-348. https://doi.org/10.1111/j.1365-2788.2005.00781.x

Nowicki, E.A. \& Sandieson, R. (2002). A meta-analysis of school-age children's attitudes towards persons with physical or intellectual disabilities. International Journal of Disability, Development and Education, 49(3), 243-265. https://doi.org/10.1080/1034912022000007270

Ossa, C. (2013). Actitudes de estudiantes sobre personas con discapacidad en la universidad del Bío-Bío. Psicogente, 32-42. http://revistas.unisimon.edu.co/index.php/psicogente/article/view/1939

Peralta, A. (2007). Libro blanco sobre universidad y discapacidad. Real Patronato sobre Discapacidad, CERMI/Fundación Vodafone España/ANECA. http://hdl.handle.net/11181/3015

Pettigrew, T.F. \& Trop, L.R. (2006). A meta-analytic test of intergroup contact theory. Journal of Personality and Social Psychology, 90(5), 751-783. https://doi.org/10.1037/0022-3514.90.5.751 
Polo, M.T. \& Aparicio, M. (2018). Primeros pasos hacia la inclusión: Actitudes hacia la discapacidad de docentes en educación infantil. Revista de Investigación Educativa, 36(2), 365-379. http://dx.doi.org/10.6018/rie.36.2.279281

Polo, M.T., Fernández, C. \& Díaz, C. (2011). Estudio de las actitudes de estudiantes de Ciencias Sociales y Pedagogía. Universitas Psychologica, 10(1), 113-123. http://www.redalyc.org/articulo.oa?id $=64719284010$

Rello, C.F., Garoz, I. \& Tejero, C.M. (2020). Cambiando las actitudes hacia la discapacidad: diseño de un programa de sensibilización en Educación Física. Retos, 37(37), 713-721. https://dialnet.unirioja.es/servlet/articulo?codigo $=7243341$

Rillota F. \& Nettelbeck, T. (2007). Effects of an awareness program on attitudes of students without an intellectual disability towards persons with an intellectual disability. Journal of Intellectual \& Developmental Disability, 32(1), 19-27. https://doi.org/10.1080/13668250701194042

Rodríguez, A. \& Fernández, A.D. (2017). Adultos que conforman menores en una escuela de colores. Actitudes de progenitores y profesores ante la diversidad cultural. Revista de Investigación Educativa, 35(2), 465-482. https://doi.org/10.6018/rie.35.2.256371

Shannon, C.D., Schoen, B. \& Tansey, T.N. (2009). The effect of contact, context, and social power on undergraduate attitudes toward persons with disabilities. Journal of Rehabilitation, 75(4), 11-18. https://search.proquest.com/docview/236401670?pqorigsite $=$ gscholar

Slininger, D., Sherrill, C. \& Jankowski, C. M. (2000). Children's attitudes toward peers with severe disabilities: Revisiting contact theory. Adapted Physical Activity Quarterly, 17(2), 176-196. https://doi.org/10.1123/apaq.17.2.176

Suriá, R. (2011). Análisis comparativo sobre las actitudes de los estudiantes hacia sus compañeros con discapacidad. Electronic Journal of Research in Educational Psychology, 9(1), 197-216. http://www.redalyc.org/articulo.oa?id=293122834010

UNESCO (2017). La educación transforma vidas. UNESCO.

Vignes, C., Godeau, E., Sentenac, M., Coley, N., Navarro, F., Grandjean, H. \& Arnaud, C. (2009). Determinants of students' attitudes towards peers with disabilities. Developmental Medicine and Child Neurology, 51(6), 473-479. https://doi.org/10.1111/j.1469-8749.2009.03283.x

Wong, D. (2008). Do contacts make a difference? The effects of mainstreaming on student attitudes toward people with disabilities. Research in Developmental Disabilities, 29(1), 70-82. https://doi.org/10.1016/j.ridd.2006.11.002

Yazbeck, M., McVilly, K. \& Parmenter, T.R. (2004). Attitudes toward people with intellectual disabilities. Journal of Disability Policy Studies, 15, 97-111. https://doi.org/10.1177/10442073040150020401

Zambrano, R.M. \& Orellana, M.D. (2018). Actitudes de los docentes hacia la inclusión escolar de niños con autismo. Killkana sociales: Revista de Investigación Científica, 2(4), 39-48. https://doi.org/10.26871/killkana_social.v2i4.296 


\section{Anexo 1.}

Cuestionario para la Valoración de las Actitudes hacia la Diversidad del Alumnado (VADA)

\section{Introducción para el centro educativo}

El cuestionario VADA se ha diseñado para conocer las actitudes de los estudiantes de Educación Infantil y Educación Primaria hacia la diversidad del alumnado. A fin de hacer accesible el cuestionario a los niños, cada ítem incluye una secuencia de imágenes adecuada a su edad. Igualmente, irán acompañados de explicaciones del encuestador. El niño deberá seleccionar un final para cada una de las secuencias que se le presenta.

\section{Cuestionario para la valoración de las actitudes hacia la diversidad del alumnado (VADA)}

\section{DATOS DE IDENTIFICACIÓN}

1.- Centro:
2.- CURSO
(1) $1^{\circ} \mathrm{El}$
(2) $2^{\circ} \mathrm{El}$
(3) $3^{\circ} \mathrm{EP}$
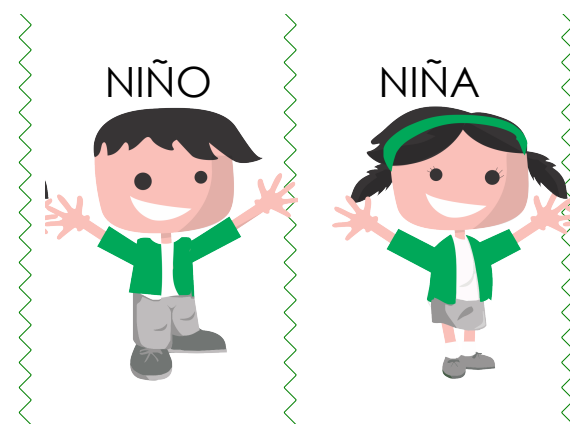

¿CUÁNTOS AÑOS TIENES?

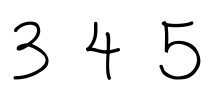

A CONTINUACIÓN TE PRESENTAMOS UNA HISTORIA A LA QUE LE FALTA EL FINAL. MARCA CON UNA X la imagen que crees que ocurrirá. 
1. EN LA ESCUELA, UN ESTUDIANTE CON DISCAPACIDAD ES CAPAZ DE SEGUIR INSTRUCCIONES COMPLEJAS
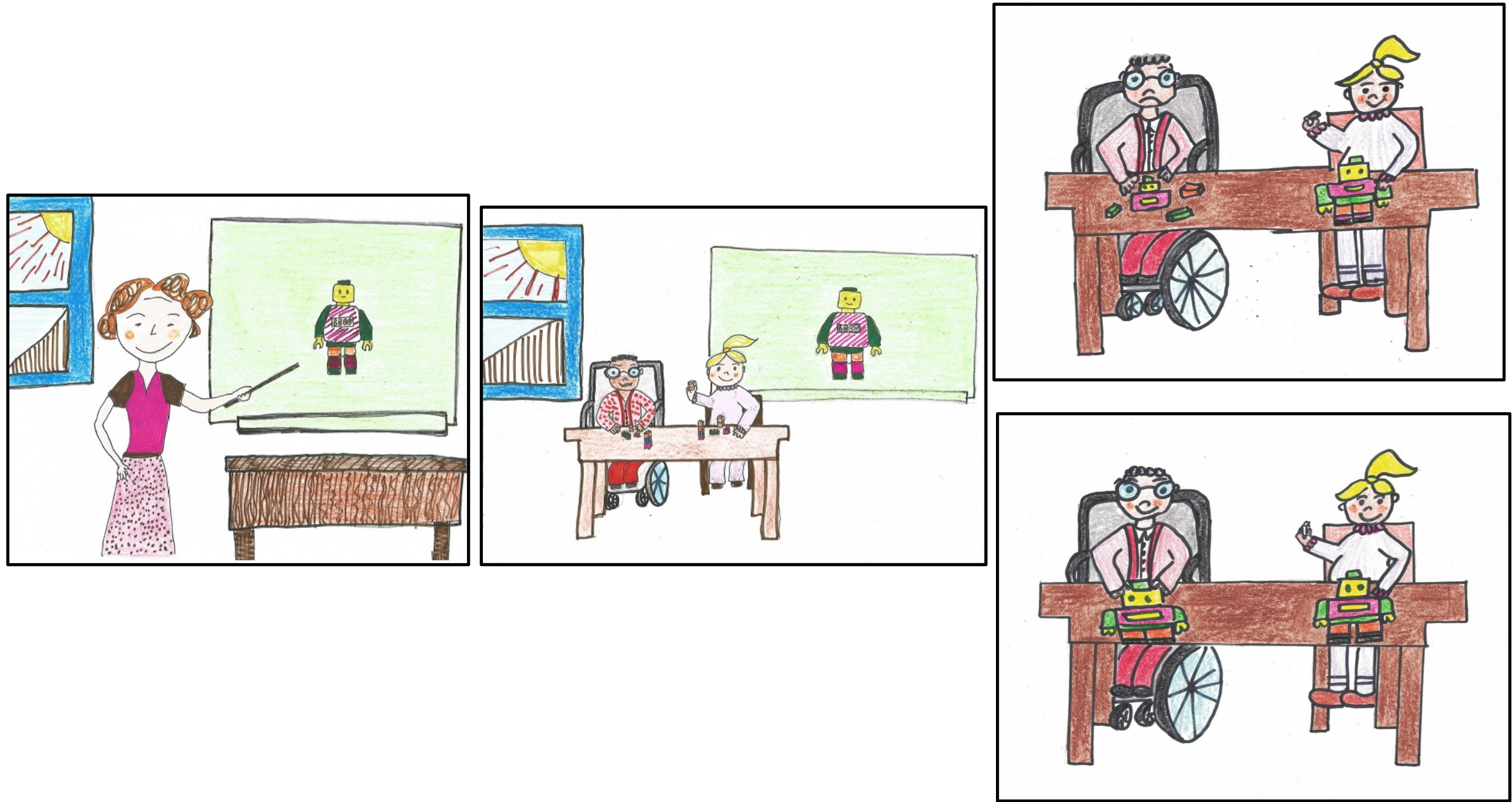
2. LOS NIÑOS Y NIÑAS DIFERENTES DEBERIAN PODER DIVERTIRSE CON LOS DEMÁS NIÑOS
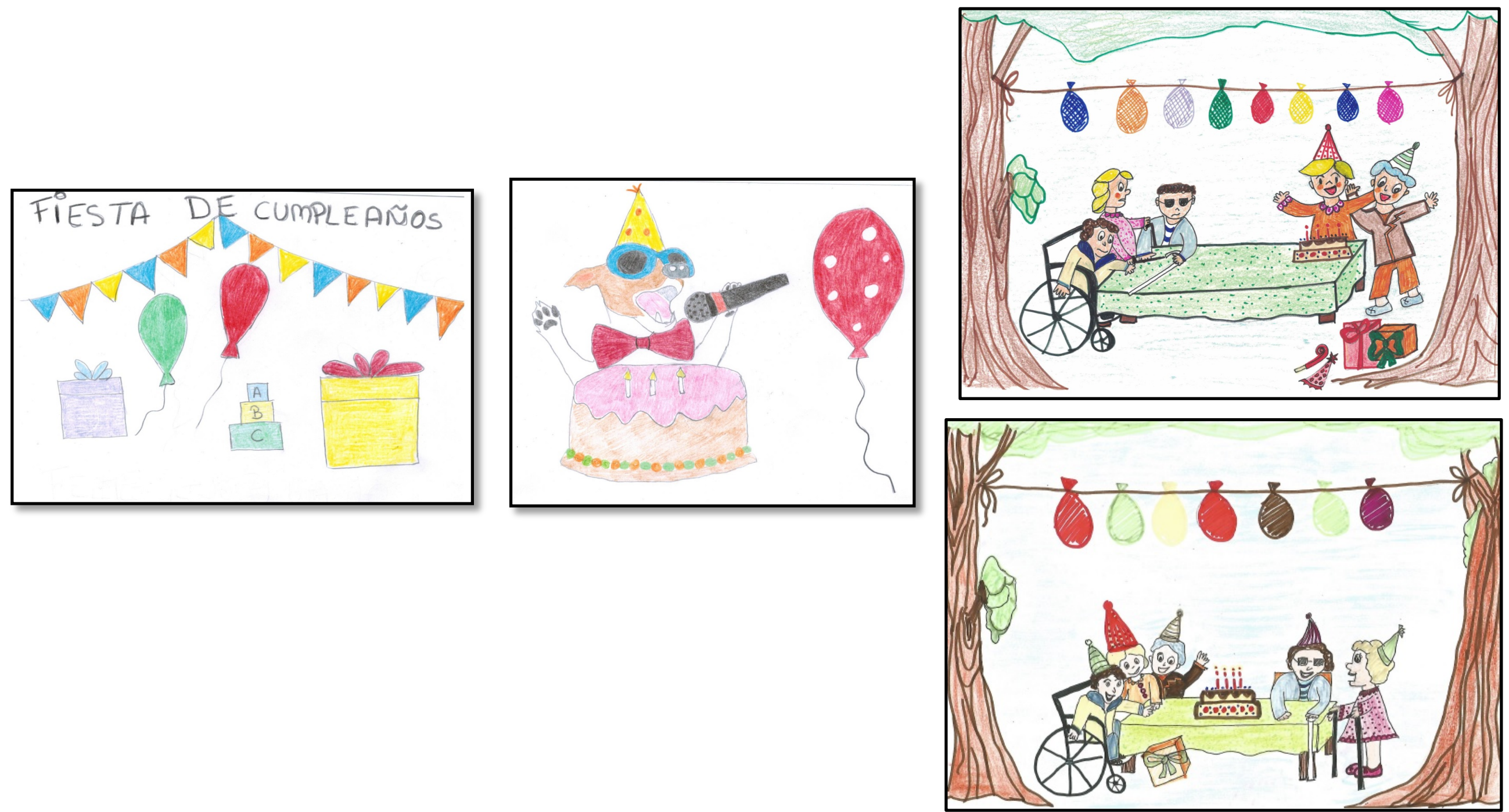
3. ME GUSTA JUGAR JUNTO A NIÑOS Y NIÑAS DIFERENTES
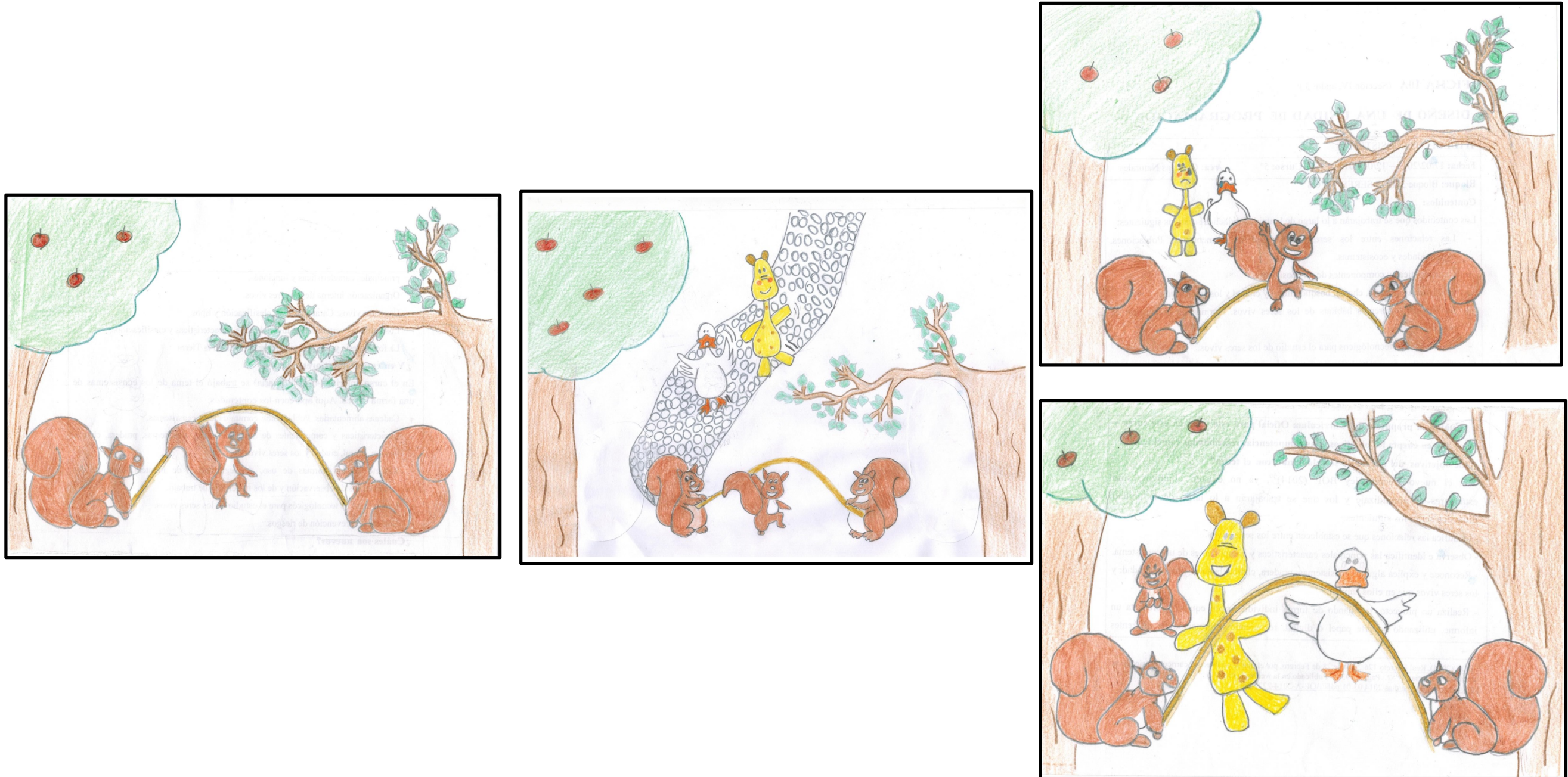
4. A LOS NIÑOS Y NIÑAS CON DISCAPACIDAD SE DEBE PERMITIR PARTICIPAR EN ACTIVIDADES GRUPALES

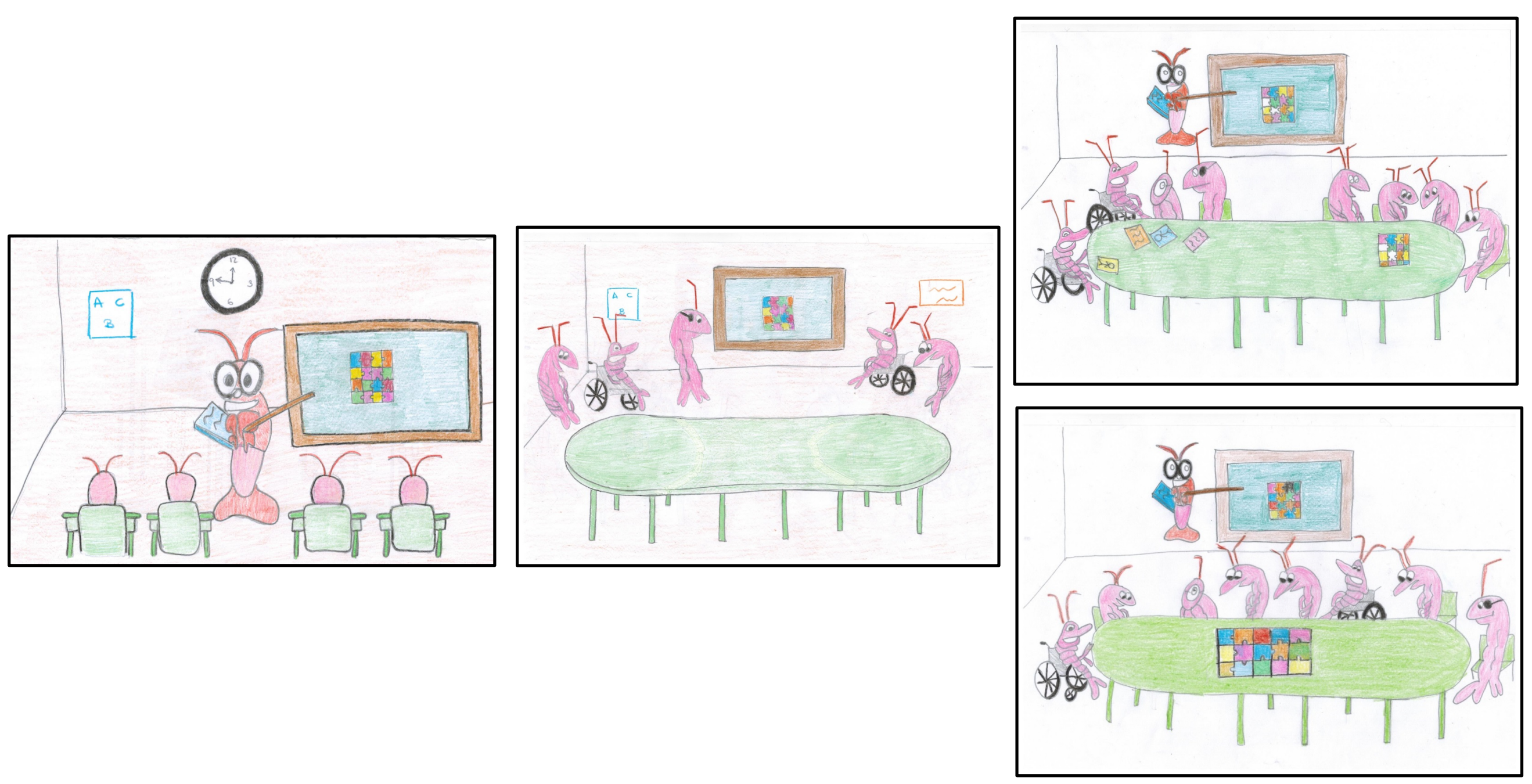


5. LOS NIÑOS Y NIÑAS CON DISCAPACIDAD PUEDEN SER ESTUDIANTES COMPETENTES EN SUS APRENDIZAJES
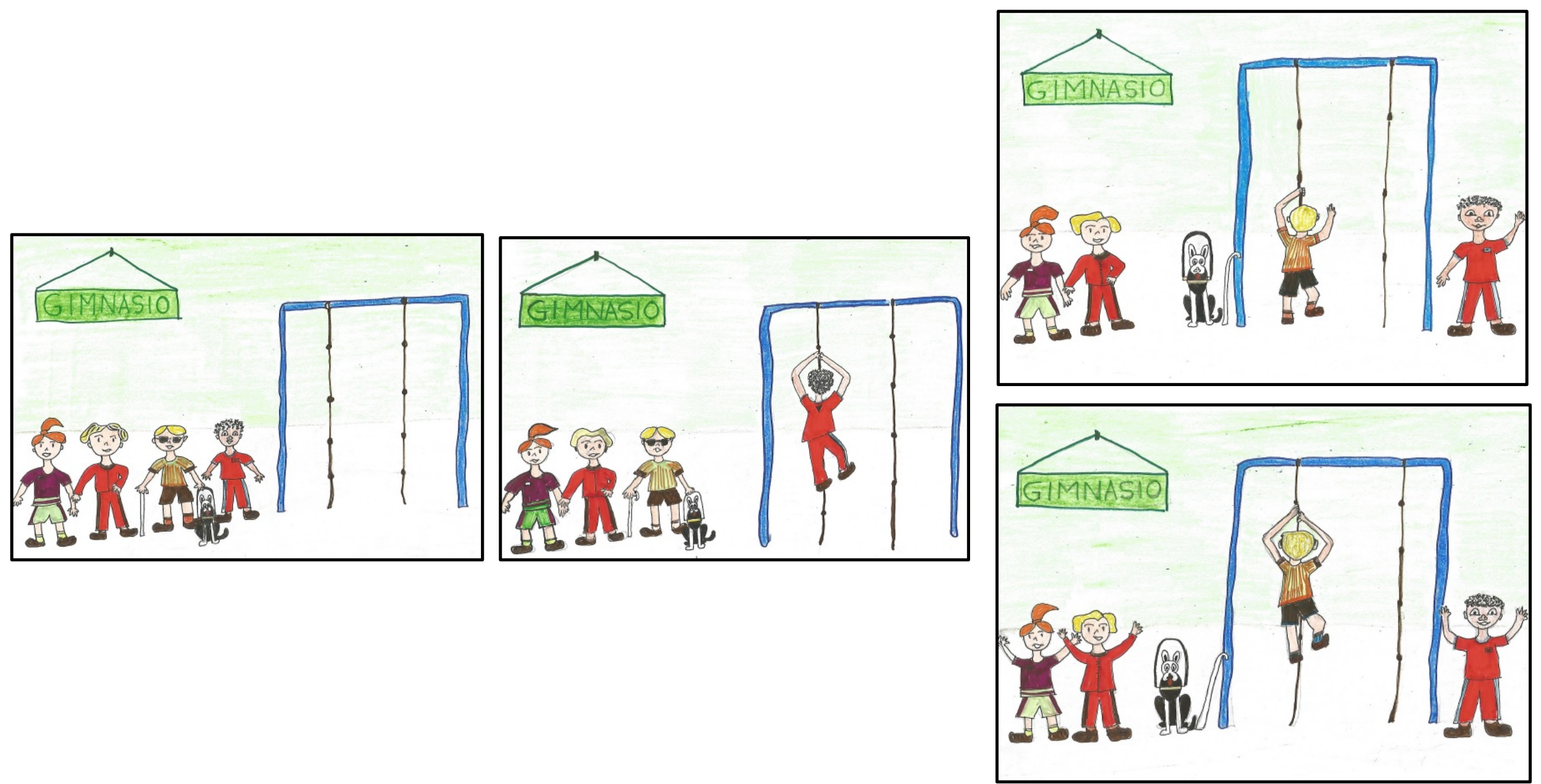
6. NO ME IMPORTA ESTAR CERCA DE NIÑOS QUE PARECEN DIFERENTES O ACTÚAN DE FORMA DISTINTA

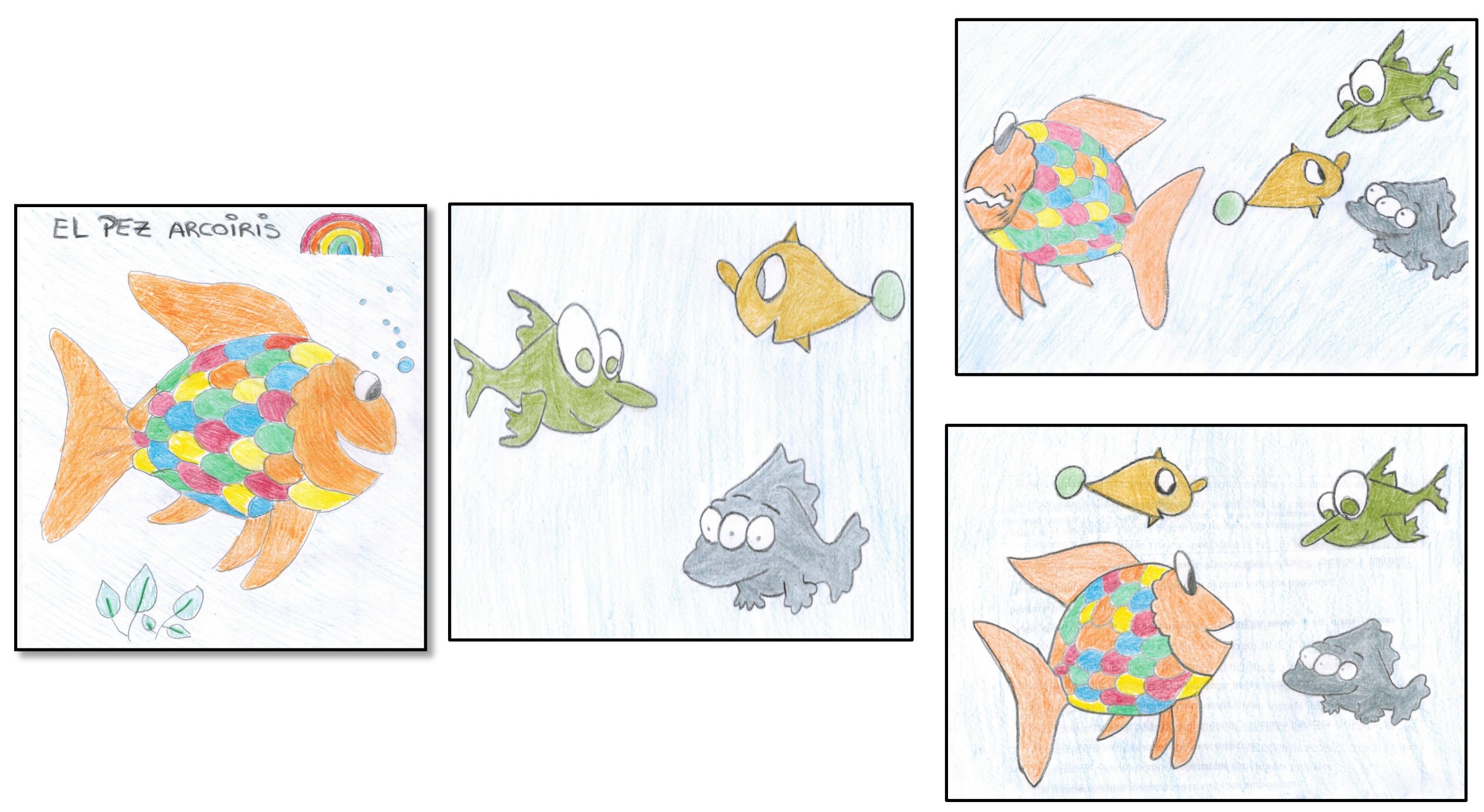


7. DE LOS ESTUDIANTES CON DISCAPACIDAD PUEDE ESPERARSE LO MISMO QUE DE LOS QUE NO LA TIENEN
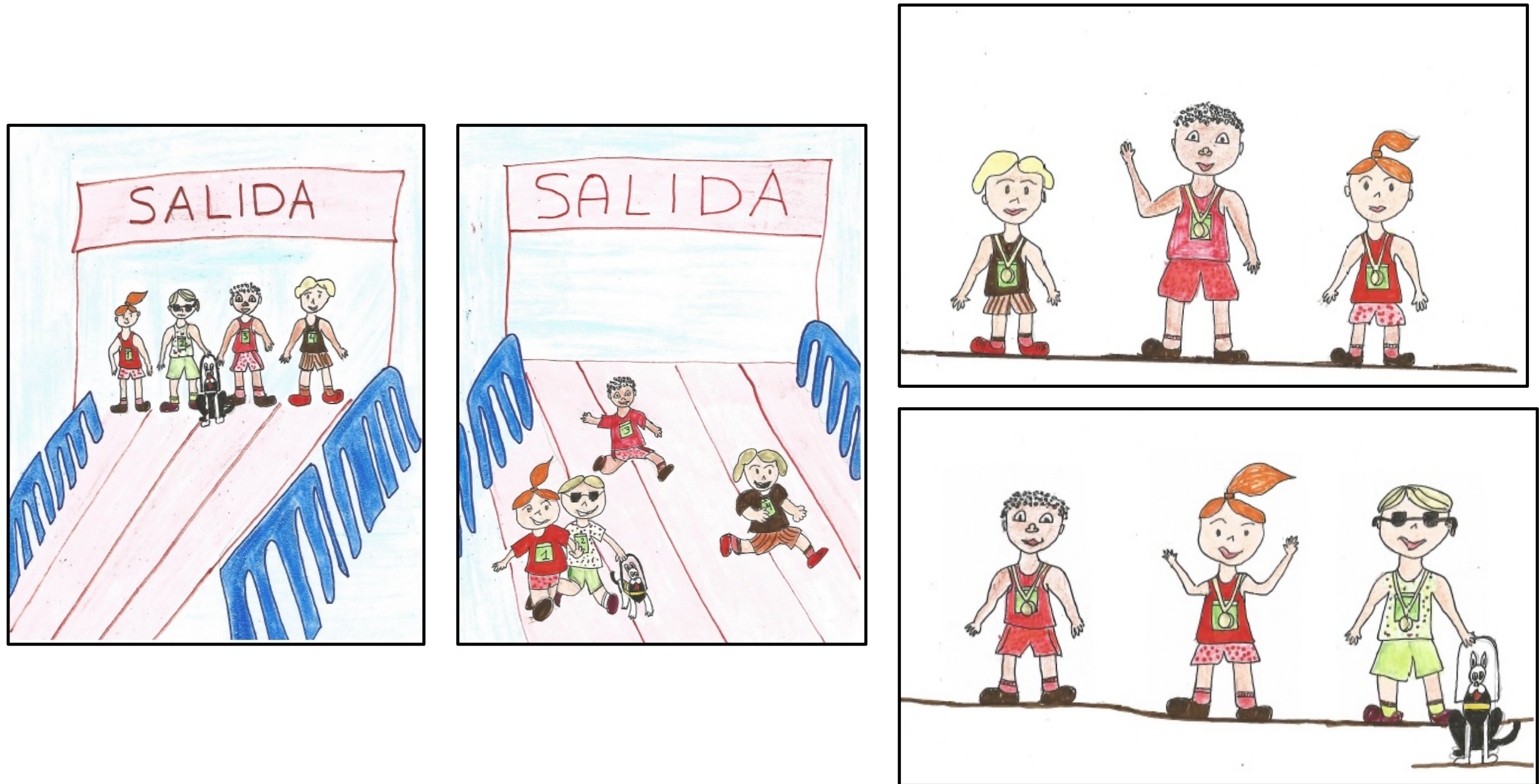
8. ES APROPIADO QUE LOS NIÑOS Y NIÑAS CON DISCAPACIDAD JUEGUEN CON TODOS LOS DEMÁS
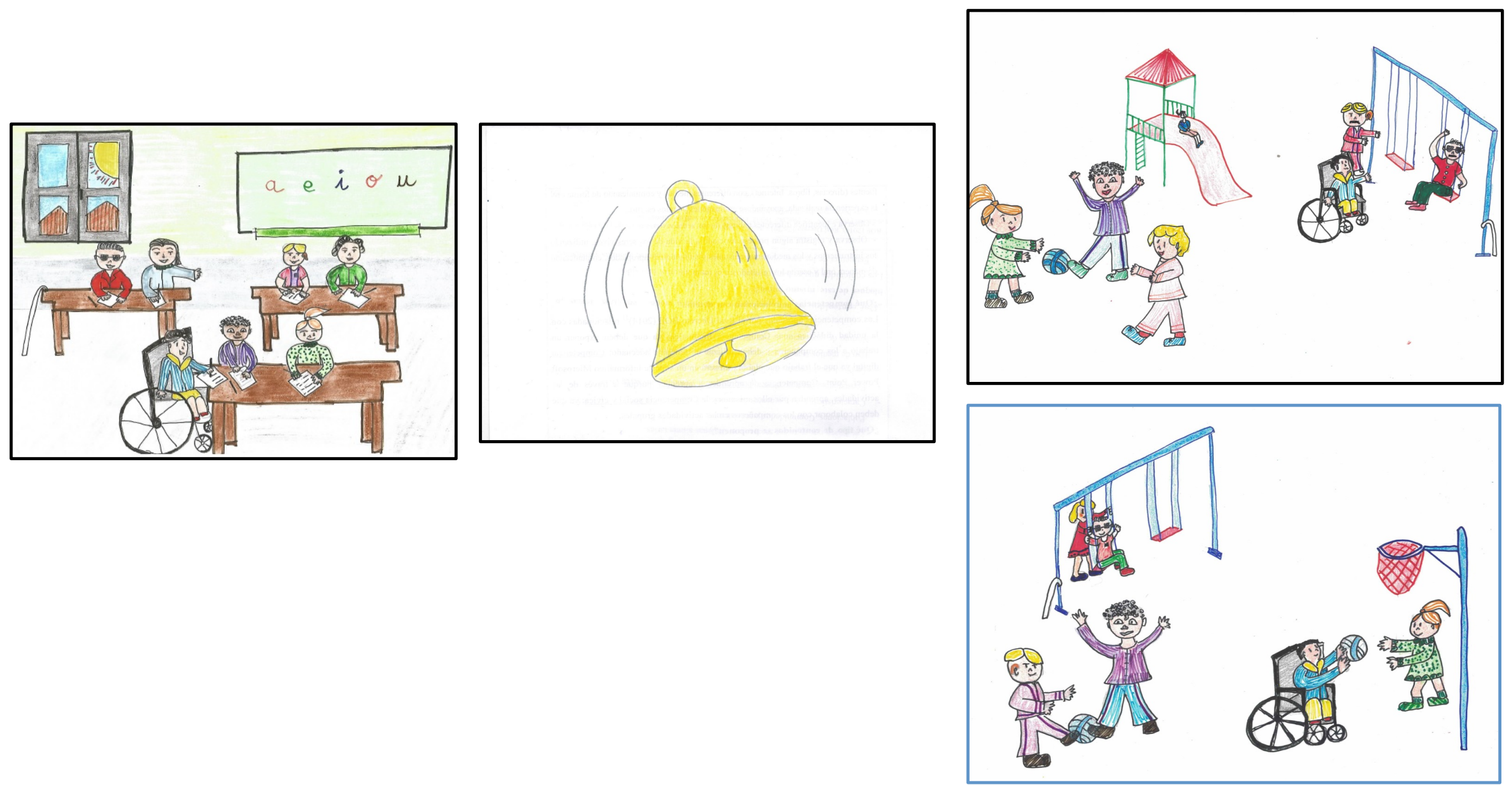
9. LOS NIÑOS Y NIÑAS DIFERENTES PUEDEN SER IGUAL DE CAPACES ACADÉMICAMENTE QUE LOS DEMÁS ESTUDIANTES
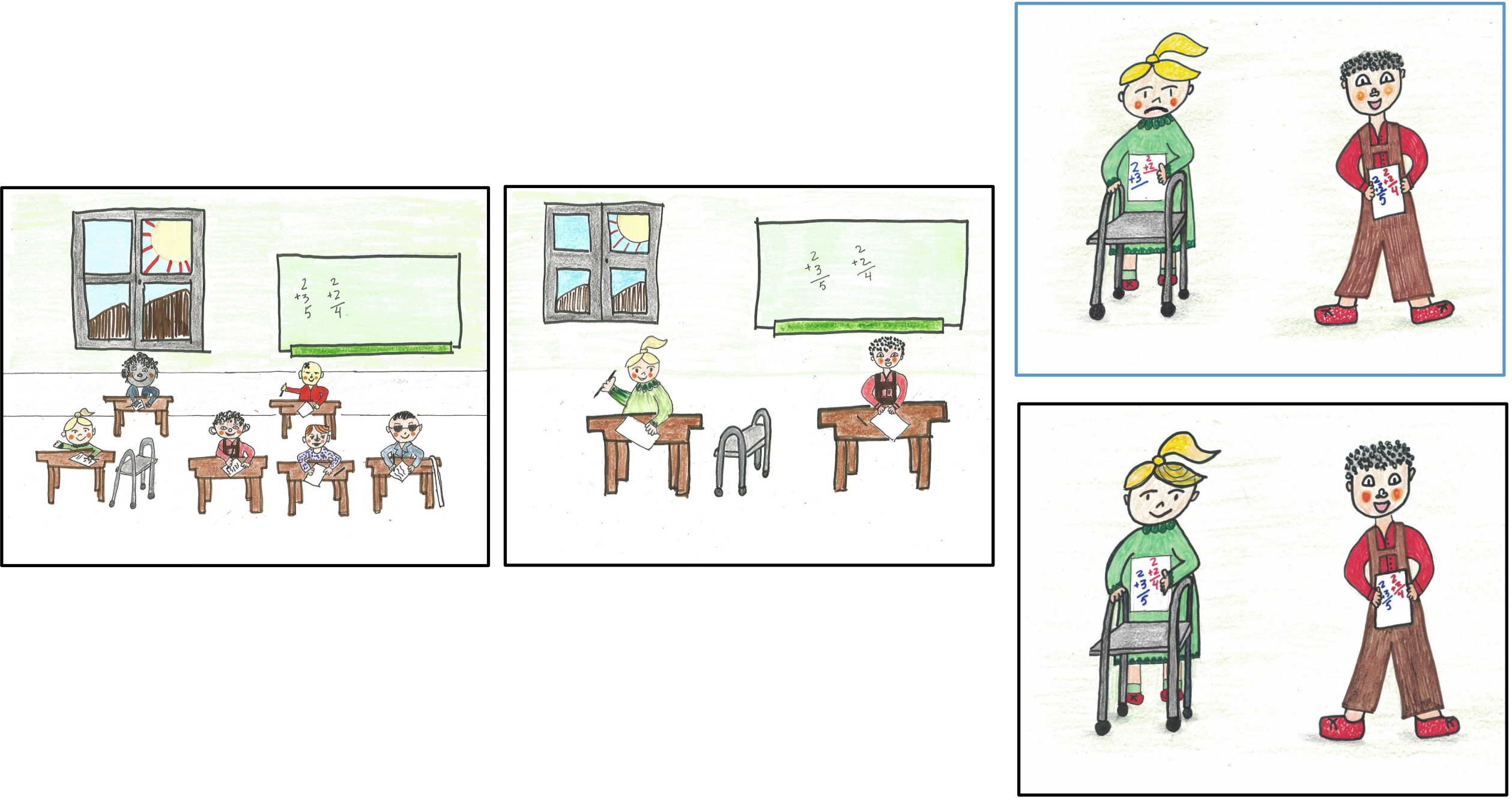
1O.ME GUSTA REALIZAR ACTIVIDADES EN EL COLEGIO CON NIÑOS Y NIÑAS DIFERENTES

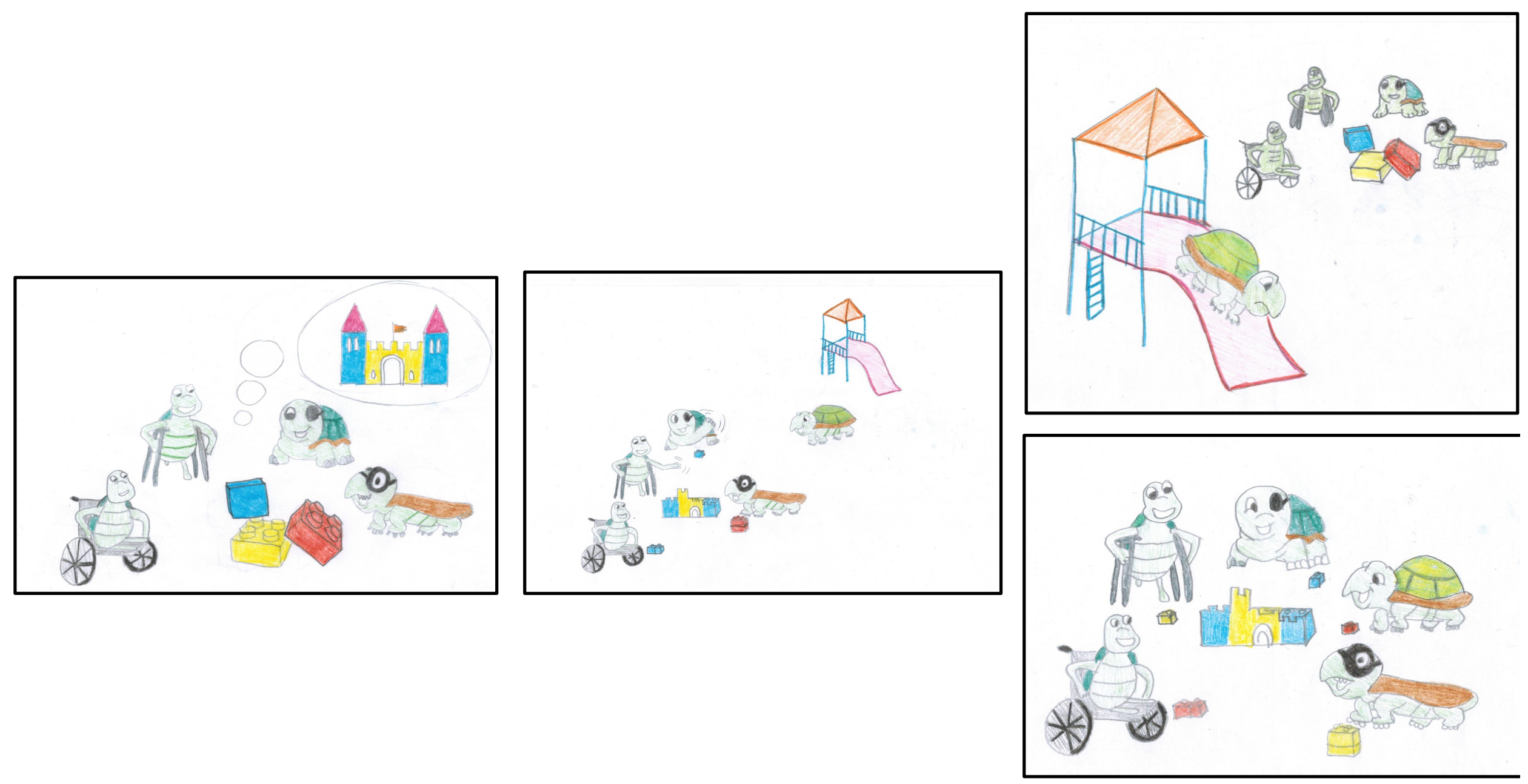

GRACIAS POR TU COLABORACIÓN 